University of Wollongong

Research Online

Australian Institute for Innovative Materials -

Papers

Australian Institute for Innovative Materials

$1-1-2016$

Critical thickness of phenolic resin-based carbon interfacial layer for improving long cycling stability of silicon nanoparticle anodes

Wei Luo

Donghua University

Yunxiao Wang

University of Wollongong, yunxiao@uow.edu.au

Shulei Chou

University of Wollongong, shulei@uow.edu.au

Yanfei Xu

University of Wollongong, yx867@uowmail.edu.au

Wei Li

Fudan University

See next page for additional authors

Follow this and additional works at: https://ro.uow.edu.au/aiimpapers

Part of the Engineering Commons, and the Physical Sciences and Mathematics Commons

Research Online is the open access institutional repository for the University of Wollongong. For further information contact the UOW Library: research-pubs@uow.edu.au 


\title{
Critical thickness of phenolic resin-based carbon interfacial layer for improving long cycling stability of silicon nanoparticle anodes
}

\author{
Abstract \\ Silicon has a high theoretical capacity, still limits its application on Si-based anodes due to the problems \\ of low electric conductivity, large volume change, continuous formation of unstable solid electrolyte \\ interphase layer, and easy fracture during lithiation and delithiation process. Despite various carbon \\ coating approaches are developed to fabricate carbon coated silicon core-shell and yolk-shell \\ nanocomposites with improved electrochemical performance, the challenges including poor long-term \\ cyclability, low Si mass ratio, and scalability remains. To overcome these challenges, we design an \\ interfacial microporous carbon coating strategy on silicon nanoparticles to form homogeneous coaxial \\ core-shell nanostructures. This synthesis sol-gel approach is simple, easy to scale up, and direct growth \\ phenolic resins on the surface with uniform and controllable thickness. Additionally, the fabricated carbon \\ layers form the microporous structures and phenolic resin frameworks, thus enabling the fast lithium ion \\ transport and formation of stable solid electrolyte interphase film. By finely controlling the thickness of \\ this phenolic resin-based carbon of $10 \mathrm{~nm}$, excellent protection of silicon nanoparticles as well as high \\ electrochemical performance are achieved, delivering a high capacity of $1006 \mathrm{~mA} \mathrm{~h} \mathrm{~g}-1$ and Coulombic \\ efficiency of $>99.5 \%$ after 500 times at a current density of $500 \mathrm{~mA} \mathrm{~g}-1$. \\ Disciplines \\ Engineering | Physical Sciences and Mathematics

\section{Publication Details} \\ Luo, W., Wang, Y., Chou, S., Xu, Y., Li, W., Kong, B., Dou, S. Xue., Liu, H. \& Yang, J. (2016). Critical thickness \\ of phenolic resin-based carbon interfacial layer for improving long cycling stability of silicon nanoparticle \\ anodes. Nano Energy, 27 255-264.
}

\section{Authors}

Wei Luo, Yunxiao Wang, Shulei Chou, Yanfei Xu, Wei Li, Biao Kong, S X. Dou, Hua-Kun Liu, and Jianping Yang 


\section{Critical Thickness of Phenolic Resin-Based Carbon Interfacial Layer for Improving Long Cycling Stability of Silicon Nanoparticle Anodes}

Wei Luo $^{\mathrm{a}}$, Yunxiao Wang ${ }^{*}$, Shulei Chou ${ }^{\mathrm{b}}$, Yanfei Xu' ${ }^{\mathrm{b}}$, Wei $\mathrm{Li}^{\mathrm{c}}$, Biao Kong ${ }^{\mathrm{c}}$, Shi

Xue Dou ${ }^{\mathrm{b}}$, Hua Kun Liu ${ }^{\mathrm{b}}$, Jianping Yang ${ }^{* a b c}$

${ }^{a}$ State Key Laboratory for Modification of Chemical Fibers and Polymer Materials, College of Materials Science and Engineering, Donghua University, Shanghai 201620, P. R. China.

${ }^{\mathrm{b}}$ Institute for Superconducting \& Electronic Materials, Australian Institute of Innovative Materials, University of Wollongong, Innovation Campus, Squires Way, North Wollongong, NSW 2500, Australia

${ }^{c}$ Department of Chemistry, Laboratory of Advanced Materials, Fudan University, Shanghai 200433, P. R. China

E-mail: yunxiao@uow.edu.au (Y.Wang); zcjpyang@gmail.com (J. Yang) 
ABSTRACT: Silicon has a high theoretical capacity, still limits its application on Si-based anodes due to the problems of low electric conductivity, large volume change, continuous formation of unstable solid electrolyte interphase layer, and easy fracture during lithiation and delithiation process. Despite various carbon coating approaches are developed to fabricate carbon coated silicon core-shell and yolk-shell nanocomposites with improved electrochemical performance, the challenges including poor long-term cyclability, low Si mass ratio, and scalability remains. To overcome these challenges, we design an interfacial microporous carbon coating strategy on silicon nanoparticles to form homogeneous coaxial core-shell nanostructures. This synthesis sol-gel approach is simple, easy to scale up, and direct growth phenolic resins on the surface with uniform and controllable thickness. Additionally, the fabricated carbon layers form the microporous structures and phenolic resin frameworks, thus enabling the fast lithium ion transport and formation of stable solid electrolyte interphase film. By finely controlling the thickness of this phenolic resin-based carbon of $10 \mathrm{~nm}$, excellent protection of silicon nanoparticles as well as high electrochemical performance are achieved, delivering a high capacity of $1006 \mathrm{~mA} \mathrm{~h} \mathrm{~g}^{-1}$ and Coulombic efficiency of $>99.5 \%$ after 500 times at a current density of $500 \mathrm{~mA} \mathrm{~g}^{-1}$.

KEYWORDS: porous carbon, core shell, sol-gel coating, silicon nanoparticles, lithium ion batteries. 


\section{Introduction}

In pursuit of rechargeable lithium-ion batteries (LIBs) as the large energy-storage devices, the electrode materials must possess high capacity, excellent rate capacity, huge energy-density, and long cycle life.[1-3] With great progress achieved, it is well recognized nowadays that the interfacial surface structures are of critical importance for improving electrochemical performance of electrode materials.[4-7] Surface modification of electrode materials by coatings are effective approaches to avoid the direct contact with electrolyte and suppress the structure transformation, thus minimizing the side reaction originated from the electrode/electrolyte interfaces, guaranteeing the structural stability and enhancing the battery performances while preventing the fast decay in capacity.[8-13] Of the various currently available coating materials, carbon encapsulated on the surface of active electrode materials, rather than simply mixing, has been demonstrated as a promising way to increase the cycling life in all-solid-state batteries.[4, $10,14,15]$ The additional benefit is that the carbon coating layer can provide superior electronic conductivity. Considerable efforts have be made in developing various sources and approaches for carbon coating on the surface of electrode materials, such as the using glucose,[16] dopamine,[17] acetylene,[18] citric acid,[15] and polyvinylidene fluoride as the precursors accompanied with the hydrothermal, sol-gel, chemical vapor deposition, and pyrolysis carbonization methods.[19, 20] The conformal coating, however, is a critical issue because the uncovered surface of active materials still suffers from the side reaction with electrolyte, partly losing the protection, and leading to the capacity decay after long term cycles.[16, 21] Therefore, it is challenge and highly desirable to realize the uniform carbon coating with well controllable thickness.[22] 
On the other hand, silicon ( $\mathrm{Si}$ ) is considered as an appealing anode material for nextgeneration LIBs, mainly because Si reaches highest theoretical specific capacity of $4200 \mathrm{~m} \mathrm{Ah} \mathrm{g}{ }^{-}$ ${ }^{1}$ (formation of $\mathrm{Li}_{4.4} \mathrm{Si}$ in full lithiation state), delivering a remarkable increment compared with that of commercial graphite carbon anode (372 $\left.\mathrm{m} \mathrm{Ah} \mathrm{g}^{-1}, \mathrm{Li}_{6} \mathrm{C}\right) \cdot[23-25]$ However, a major problem associated with $\mathrm{Si}$ is the inevitable large volume changes (>300\%) during lithium alloy/dealloy reaction, which results the undesired cracking, loss of electric contact, unstable growth of solid electrolyte interphase (SEI), and finally, fast fading of capacity.[26] Besides, the low intrinsic electrical conductivity $\left(1.56 \times 10^{-3} \mathrm{~S} \mathrm{~m}^{-1}\right)$ and lithium diffusivity of silicon also limits its electrochemical performance.[27-29] The formation of silicon-carbon nanocomposites has been considered as a very promising strategy and widely exploited to increase the lifetime of silicon anode.[30-39] In such composites, the carbon layer not only enhances the electrical conductivity of the anodes benefited the fast lithium transport, but also isolates the contact of $\mathrm{Si}$ with electrolyte, prevents the continuous growth of SEI film, and provides the structural buffer to relieve the volume change, thus delivering the integrity of electrode and high performance. More recently, significant achievements has been made to fabricate the void-involved carbon coating on silicon nanoparticls, including the yolk-shell-structured silicon@void@carbon,[18, 40, 41] pomegranate-like Si structures,[42] and yolk-shell Si@mesoporous-carbon nanoparticles,[43] for improvement the long cycling stability of Si-based anodes.[44-48] However, the introduction of void space usually engenders new problems, which are critical challenges for the large-scale use and practical application.[39] First, the creation of void spaces usually adopts $\mathrm{SiO}_{2}$ as the sacrificing template layer and removing it by selective etching using hydrofluoric acid, leading to multistep and complex synthesis procedures and toxic reagents.[45, 49] Second, these yolk-shell nanocomposites are difficult to deliver satisfing mass loading of silicon active materials and tap 
density, caused by the existence of large void space, thus presenting relativly low reversible capacity.[18, 22] Therefore, exploring a simple and scalable approach to realize the uniform controllable carbon coating with high capacity after long-term cycling, is of scientific and technologic importance.[50, 51]

Herein, we introduce a phenolic resin-based carbon interfacial coating on the surface of silicon nanoparticles to form the core-shell structures as the anode materials. The carbon coating layer is uniform and can be well controlled from 2 to $25 \mathrm{~nm}$ through a facile sol-gel method by using resorcinol and formaldehyde as the precursor and hexadecyltrimethylammonium bromide as the surfactant in the water-ethanol-ammonia solution. The critical thickness of phenolic resin-based carbon layers are investigated by electrochemical performances tests. The carbon interfacial layer with $10 \mathrm{~nm}$-thick has the best cycling stability, and delivers a high capacity of $1006 \mathrm{~mA} \mathrm{~h}$ $\mathrm{g}^{-1}$ after 500 cycles at the current density of $500 \mathrm{~mA} \mathrm{~g}^{-1}$.

\section{Experimental Section}

Synthesis of Si@C Core-Shell Nanoparticles: The commercial silicon nanoparticles with a diameter of $80 \mathrm{~nm}$ (purchased from Nanostructured and Amorphous Materials) were selected coated with a well-controlled thickness of resorcinol-formaldehyde resin (RF) polymer layer via a surfactant template sol-gel coating method and following carbonization. For the typical preparation of carbon coated silicon with the thickness of $10 \mathrm{~nm}$ (Si@ 10C), $0.3 \mathrm{~g}$ of commercial silicon nanoparticles and $0.92 \mathrm{~g}$ of hexadecyltrimethylammonium bromide (CTAB) were added into $28.16 \mathrm{~mL}$ of deionized water and ultrasonic treated for $30 \mathrm{~min}$ to form homogeneous mixture. This was followed by addition of ethanol $(11.28 \mathrm{~mL})$, resorcinol $(0.28 \mathrm{~g})$, and ammonia $(0.1 \mathrm{~mL})$, subsequent stirred at $35{ }^{\circ} \mathrm{C}$ for $30 \mathrm{~min}$. Afterwards, $0.4 \mathrm{~mL}$ of formaldehyde was 
added dropwise into the mixed solution. The reaction was allowed to proceed for $6 \mathrm{~h}$ at $35{ }^{\circ} \mathrm{C}$ under continuous stirring, and then aged without disturbance at room temperature for $12 \mathrm{~h}$. The Si@RF core-shell nanoparticles were collected by centrifugation and washing with deionized water and ethanol several times. Finally, the Si@10C core-shell nanoparticles were obtained after calcination under nitrogen atmosphere at $700{ }^{\circ} \mathrm{C}$ for $3 \mathrm{~h}$ with the heating rate of $2{ }^{\circ} \mathrm{C} / \mathrm{min}$. The thickness of carbon coating layer can be well-tailored by corresponding change the addition amount of silicon nanoparticles, resorcinol and formaldehyde. For example, if the resorcinol amount was changed from $0.02,0.14$, and $0.70 \mathrm{~g}$, the prepared carbon coating layer with the thickness of 2 ( $\mathrm{Si} @ 2 \mathrm{C}), 5$ ( $\mathrm{Si} @ 5 \mathrm{C})$, and 15 (Si@15C) nm, respectively. The Si@25C core-shell nanoparticles with the coating layer of $25 \mathrm{~nm}$ also can be synthesized with the reduction amount of silicon nanoparticle $(0.15 \mathrm{~g})$ at high concentration of resorcinol $(0.70 \mathrm{~g})$ condition.

Characterization: The morphologies of the samples were observed on a Hitachi S-4800 (Japan) field-emission scanning electron microscope (FESEM). The nanostructures were characterized by transmission electron microscopy (TEM, JEOL JEM-ARM200F). The samples were suspended in ethanol and dried on a holey carbon support film on a $\mathrm{Cu}$ grid for TEM measurements. The crystal structure and phase of products were characterized using wide-angle X-ray diffraction (XRD, Bruker D8, Germany) with Ni-filtered $\mathrm{Cu}$ Ko radiation (40 kV, $40 \mathrm{~mA}$ ). The thermal decomposition behavior of the products was monitored by using a Mettler Toledo TGA/SDTA851 analyzer from 50 to $900{ }^{\circ} \mathrm{C}$ in air with a heating rate of $10^{\circ} \mathrm{C} / \mathrm{min}$. The Raman spectra were collected in the wavenumber range of $200-2000 \mathrm{~cm}^{-1}$, and the peak intensities and positions were normalized to the standard silicon wafer at $520 \mathrm{~cm}^{-1}$. The porosity was measured by nitrogen sorption isotherms at $77 \mathrm{~K}$ with a Micromeritics Tristar 3020 analyzer (USA). Before measurements, the samples were degassed in vacuum at $180{ }^{\circ} \mathrm{C}$ for at least $6 \mathrm{~h}$. The 
Brunauer-Emmett-Teller (BET) method was utilized to calculate the specific surface areas $\left(\mathrm{S}_{\mathrm{BET}}\right)$, using adsorption data in a relative pressure $\left(\mathrm{P} / \mathrm{P}_{0}\right)$ range from 0.04 to 0.2 . The pore volume and pore size distributions were derived from the adsorption branches of isotherms by using the Barrett-Joyner-Halenda $(\mathrm{BJH})$ model. The total pore volume, $\mathrm{V}_{\mathrm{t}}$, was estimated from the amount adsorbed at a relative pressure $\mathrm{P} / \mathrm{P}_{0}$ of 0.995 .

Electrochemical characterizations: The electrochemical measurements were conducted by assembling coin-type half cells in an argon-filled glove box. The electrode slurry was prepared by mixing 60 wt. \% active material (Pristine Si nanoparticles, Si@C core-shell nanoparticles), 10 wt. \% Super $\mathrm{P}^{\circledR}, 10$ wt. \% multi-walled carbon nanotubes, and 20 wt. \% carboxymethyl cellulose (CMC) in a planetary mixer (KK-250S). The electrode films were prepared by pasting the slurry on copper foil using a doctor blade to a thickness of $100 \mu \mathrm{m}$, which was followed by drying in a vacuum oven at $80^{\circ} \mathrm{C}$ overnight. The working electrodes were prepared by punching the electrode film into discs $0.96 \mathrm{~cm}$ in diameter. Lithium foil was employed for both reference and counter electrodes. The electrodes were separated by a Celgard separator. The electrolyte was 1.0 $\mathrm{M} \mathrm{LiPF}_{6}$ in 3:4:3 (weight ratio) ethylene carbonate (EC) / dimethyl carbonate (DMC) / diethylene carbonate (DEC), with 5 wt. \% fluoroethylene carbonate (FEC) additive from Novolyte Technologies. The electrochemical performances were tested with a Land Battery Test System with a cut-off voltage range from $0.005 \mathrm{~V}$ to $1.5 \mathrm{~V}\left(\mathrm{vs}\right.$. $\left.\mathrm{Li}_{/ \mathrm{Li}}{ }^{+}\right)$. Cyclic voltammetry and impedance testing were performed using a Biologic VMP-3 electrochemical workstation from $0.005 \mathrm{~V}$ to $1.5 \mathrm{~V}$ at a sweep rate of $0.01 \mathrm{mV} \mathrm{s}^{-1}$.

\section{Results}


The direct growth of microporous carbon with uniform and well-tailored thickness on silicon via a sol-gel process has proven challenging, because the uncontrollable polymerization of carbon precursors and unsuitable interfacial interactions. Here, the resorcinol/formaldehyde (RF) resins are selected as the carbon source since it easily deposits on the hydrophilic surface through four-coordinate covalently bonded frameworks by a facile sol-gel polymerization approach and converts into carbon via a simple carbonization process with high yield.[52, 53] As illustrated in Figure 1, the polymerization of resorcinol and formaldehyde is initiated on the surface of silicon nanoparticles (Si NPs) in the presence of ammonia and hexadecyltrimethylammonium bromide (CTAB), generated the uniform growth of RF resin layer, which is following transformed into carbon through calcination in nitrogen atmosphere at $700{ }^{\circ} \mathrm{C}$. In this process, the existence of a thin silicon oxide $\left(\mathrm{SiO}_{\mathrm{x}}\right)$ layer and surface $-\mathrm{OH}$ group on the $\mathrm{Si}$ nanoparticles surface plays a critical role for providing the negatively charged interface, promoting the interaction with cationic surfactant $\mathrm{CTAB}$ and triggering in situ self-assembly with polymerized RF. Once the RF growth sites are produced around the surface of Si core, the subsequently deposition of RF and CTAB prefer coaxial growth, to enable the uniform coating of RF resin layer via this facile surfactant template-directed sol-gel coating method. The shell thickness can be conveniently controlled by adjusting the addition amount of $\mathrm{Si}$ nanoparticles or the concentration of RF precursor with the fixed ratio of resorcinol to formaldehyde.

As shown by optical, field emission scanning electron microscopy (FESEM), and transmission electron microscopy (TEM) images in Figure 2, the pristine commercial Si nanoparticles are adobe brown powder consisting of spherical nanoparticle with the dominated size of $\sim 80 \mathrm{~nm}$. After coating with different thickness of carbon shell, the products obviously show the color changes, from brown to dark green and finally to black. The color change indicates the gradually 
increasing of the shell thickness and carbon contents to form the Si@C core-shell structure. Notably, as observed from the FESEM images, the spherical morphologies of the products are effectively maintained with the increased particles size from $\sim 80$ to $200 \mathrm{~nm}$. Furthermore, it can be seen from TEM images that all the Si NPs are homogenously sealed by a smooth carbon layer, leading to the formation of core-shell structured Si@C nanoparticls. These resultant coreshell nanoparticles have uniform carbon coating layers with the well-tailored thickness of $\sim 2,5$, 10, 15, and $25 \mathrm{~nm}$, respectively (denoted as $\mathrm{Si} @ \mathrm{xC}, \mathrm{x}$ representative the thickness).

Figure 3a shows the X-ray diffraction (XRD) patterns of pristine Si, Si@2C, Si@5C, Si@10C, Si@15C, and Si@25C, respectively. For all the carbon coated Si samples, six distinct diffraction peaks can be observed, which are matched well with the pristine Si nanoparticles and assigned to (111), (220), (311), (400), (331), and (422), respectively. Besides the Si phase, a weak peak at $2 \theta$ value of $22.8^{\circ}$ can be attributed the (002) plane of carbon material. These results suggest the Si@ $\mathrm{xC}$ core-shell nanoparticles with well Si crystallization and amorphous carbon coating. The amorphous carbon shells are further confirmed by Raman spectra (Figure 3b), the presence of a strong peak of $\sim 1320 \mathrm{~cm}^{-1}$ and a weak peak of $\sim 1590 \mathrm{~cm}^{-1}$, respectively, recognized as the characteristic disorder-induced D band and graphitic $\mathrm{G}$ band of carbon. In addition, the intensity of characteristic Si Raman band around $510 \mathrm{~cm}^{-1}$ is decreased, revealing the well-sealed coreshell structure. Moreover, the silicon contents in these $\mathrm{Si} @ \mathrm{xC}$ core-shell nanoparticles are measured by thermogravimetric analysis (TGA). As observed in Figure 3c, the weight loss originated from the carbon combustion occurs in the range of 450 to $700{ }^{\circ} \mathrm{C}$, followed slight weight increase due to the oxidation of silicon nanoparticle at high temperature. Thus, the mass percentages of silicon in all core-shell samples are calculated to be $\sim 96.7,90.3,81.7,51.2$, and 46.2wt\% for Si@2C, Si@5C, Si@10C,Si@15C, and Si@25C, respectively (Figure 3c and 3d). 
Based on the carbon layer thickness and silicon mass percentage, these core-shell structured nanoparticles can be categorized into high, medium, and low Si ratio, respectively (Figure 3d).

To investigate the critical carbon coating layer thickness, Si-based electrodes with the representative silicon ratio and the different carbon coating thickness of 0 (pristine Si NPs), 5 (Si@5C), 10 (Si@10C), and 15 nm (Si@15C) are selected and cycled between 0.005 and 1.5 V at the current density of $500 \mathrm{~mA} \mathrm{~g}^{-1}$ in a coin-type lithium half cell. All the capacity of electrode samples are based on the total weight of the electrode. As seen in Figure $4 \mathrm{a}$, the first reversible lithium discharge and charge capacity of Si NPs without carbon coating is estimated to be 3105 and $2254 \mathrm{~mA} \mathrm{~h} \mathrm{~g}^{-1}$, with a low initial Coulombic efficiency (ICE) of $72.6 \%$. It should be noticed that the introduction of carbon on the surface of Si NPs can significantly improve the capacity and ICE. The first discharge capacities are changed into 3774, and $3394 \mathrm{~mA} \mathrm{~h} \mathrm{~g}^{-1}$, with a high ICE of 85.8 and $74.9 \%$ for $\mathrm{Si@5C} \mathrm{and} \mathrm{Si} @ 10 \mathrm{C}$ core-shell nanoparticles, respectively (Table 1). These could be the reasons that the thin carbon layer not only enhance the electrical conductivity but also minimize side reactions with electrolytes, thus providing the large first discharge capacity and high ICE values. Simultaneously, the first cycle capacity and ICE decrease with the increasing carbon coating layer thickness from 5 to $15 \mathrm{~nm}$, caused by the reduction of silicon weight ratio and carbon irreversibly reaction with lithium at low potential. Another interesting phenomena is that after coating a carbon layer on Si NPs, the cycling stability indicates obvious improvements. Under the deep charge-discharge condition, only $20 \%$ capacity is preserved for Si NPs electrode after 40 cycles, the fast capacity fading is accordance with the previous reports.[16, 17] With the carbon coating, an increasing capacity retention of 21, 66 and $69 \%$ after 200 cycles is observed for Si@5C, Si@10C and Si@15C core-shell nanoparticles, respectively (Figure 4b). After 500 long-term cycles, Si@10C core-shell nanoparticles with the 
$10 \mathrm{~nm}$-thick carbon coating layer shows the best performance, giving the high capacity of 1006 $\mathrm{mA} \mathrm{h} \mathrm{g}{ }^{-1}$ at the large current density of $500 \mathrm{~mA} \mathrm{~g}^{-1}$, which is nearly three times the theoretical capacity of graphite (Figure 4a and Table 1). In fact, there is little capacity decay after 200 cycles for Si@10C core-shell nanoparticles. As shown in the voltage profiles of the selected cycles, the Si@10C core-shell nanoparticle electrode exhibits typical electrochemical features of crystalline silicon (Figure 4c). No obvious change in charge-discharge profiles can be found after 500 cycles for $\mathrm{Si} @ 10 \mathrm{C}$ core-shell nanoparticle electrode, demonstrating the superior cycling performance. Coulombic efficiency is another important indicator of the reversibility of electrode reaction for silicon anode. The SEI film rupture, reformation, and growth usually causes the decrease of Coulombic efficiency.[42] The Si@10C core-shell nanoparticle electrode displays a high Coulombic efficiency of $>99.5 \%$ in the following 50th to 500th cycles (Figure 4d), suggesting a very stable SEI formed outside the carbon coating layer. More importantly, the Si@10C core-shell nanoparticle electrode has excellent rate capacity, rendering the high capacities of $2864,2500,2231,1813$, and $1209 \mathrm{~mA} \mathrm{~h} \mathrm{~g}^{-1}$ at the current density of $0.28,1.4,5.6$, 11.2, and $16.8 \mathrm{~A} \mathrm{~g}^{-1}$, respectively (Figure 4e). Note also that the outstanding rate capacity retention achieves as high as $63.3 \%$ when the current density increased 40 times from 0.28 to 11.2 $\mathrm{A} \mathrm{g} \mathrm{g}^{-1}$. The superior rate capacity is believed to be highly comparable with some previous carbon coated silicon core-shell and yolk-shell electrodes reports.[16, 18, 44] Furthermore, the cyclic voltammograms $(\mathrm{CV})$ curves of Si@10C core-shell nanoparticle electrode were illustrated in Figure S1, revealing the Li-storage processes. During the first cathodic scan, two slight bumps evolve at $1.5 \mathrm{~V}$ and $\sim 0.9 \mathrm{~V}$, respectively, which are probably ascribed to the formation of solid electrolyte interphase (SEI) film and occurrence of irreversible reactions. Those two cathodic peaks, therefore, did not appear for the subsequent cycles. A predominant peak at $\sim 0.195 \mathrm{~V}$ 
becomes intensive with the proceeding of cycling, which corresponds to the lithiation reaction of $\mathrm{Si}$. Meanwhile, a sharp peak occurs at $\sim 0.02 \mathrm{~V}$, which is due to the $\mathrm{Li}$ insertion into $\mathrm{C}$ component. It is evident that the $\mathrm{Si} @ 10 \mathrm{C}$ shows two anodic peaks at $\sim 0.37$ and $0.53 \mathrm{~V}$, corresponding to the reduction processes from $\mathrm{Li}_{\mathrm{x}} \mathrm{Si}$ to amorphous $\mathrm{Si}$. With the scan proceeding, the cathodic and anodic peaks become more and more distinct, indicating the occurrence of activation process of the sample and increasing breakdown of the crystalline Si structure. In addition, the electrochemical inpedance plots of these samples after rate-capability testing are shown in Figure S2. It can be seen that Si@10C core-shell nanoparticle electrode has a much low charge transfer resistance $\left(R_{\mathrm{ct}}\right)$, enables a superior conductivity and fast lithium-ion transfer.

\section{Discussion}

The improved cycling stability and outstanding rate capacity of the Si@10C core shell nanoparticle electrode could be attributed to the unique features associated with the well-tailored phenolic resin-based carbon interfacial coating. First, the uniform and coaxial carbon coating can well protect the silicon core and minimize the side reaction. On the other hand, these core-shell nanoparticles with a thin carbon layer are aggregated into necklace-like continuous structures (Figure 2d), which enables direct and better contact with the current collector, providing fast electron transfer channels and excellent rate capability. Second, the well-fabricated carbon layer of $10 \mathrm{~nm}$ can effectively alleviate the internal stress caused by the volume change during charge and discharge process, thus avoiding the structural fracture and ensuring the long cycling stability. In contrast, the thinner carbon coating layer, such as $5 \mathrm{~nm}$, unable to sustain the strain relaxation upon the lithium insertion and extraction, leading to the pulverization of core-shell structure and poor cycling performance. Third, the microporosity of the carbon coating layer originated from the removal of CTAB surfactant and shrinkage of RF resins (Figure 2d), could 
favors the $\mathrm{Li}$ ion rapidly transport through the shell and reacted with $\mathrm{Si}$ active core even at a very high current density.[54-56] As further confirmed by the nitrogen sorption isotherms, the Si@10C core-shell nanoparticles present a typical type-I curves with a sharp capillary condensation step in the relative low pressure $\mathrm{P} / \mathrm{P}_{0}$ of $0.02-0.1$, demonstrating the presence of micropores (Figure 5a and 5b). The Brunauer-Emmett-Teller (BET) surface area and total pore volume of the sample are calculated to be $\sim 129.9 \mathrm{~m}^{2} \mathrm{~g}^{-1}$ and $0.11 \mathrm{~cm}^{3} \mathrm{~g}^{-1}$, respectively. Significantly, the micropore surface area and volume are as high as $\sim 125.1 \mathrm{~m}^{2} \mathrm{~g}^{-1}$ and $0.06 \mathrm{~cm}^{3} \mathrm{~g}^{-}$ 1. Therefore, the Si@10C core-shell nanoparticles can release the induced strain to some extent because of the short diffusion pathways and microporous characteristics. [57] Fourth, the unique texture of carbon coating layer derived from the carbonization of $\mathrm{RF}$ polymer at $700{ }^{\circ} \mathrm{C}$, which is formed of a phenolic resin frameworks composed by plenty of $\mathrm{OH}$-substituted and other aromatic carbons in phenol, and methylene linkages between phenolic rings, as seen in the ${ }^{13} \mathrm{C}$ solid-state NMR spectrum (Figure 5c). Such particular carbon frameworks is favorable for the formation of a stable SEI, as evidenced by the high Coulombic efficiency during long-term cycles (Figure 4d).[58] In addition, the SEI performance is highly dependent on the surface chemistry of carbon layer and plays a significant role in improvement the long cycling stability.[28, 42, 58] Significantly, Si@10C core-shell electrode preserves the sphercial morphology after 500 cycles test, suggesting the good structural integrity for well-designed microporous carbon layer coated Si nanoparticles (Figure 5d). It also found that this phenolic resin-based carbon interfacial layer delivers a better stability compared to other previous reported carbon source shells, including glucose, citric acid, dopamine, acetylene, and other polymers (Table 2). The results are also in good agreement with the reports of Cui's group, which have 
shown the pomegranate-like Si structures sealed by phenolic resins improving the long cycling life. $[22,42]$

To provide further evidences, the higher calcination temperature $\left(900{ }^{\circ} \mathrm{C}\right)$ of the $\mathrm{Si} @ 10 \mathrm{C}$ core shell nanoparticles ( $\mathrm{Si} @ 10 \mathrm{C}-900)$ with amorphous carbon frameworks is cycling tested (Figure S3). At the first stage, the Si@10C-900 core shell nanoparticles present nearly the same cycling stability with the Si@10C-700 electrode. However, the capacity is fast decayed during the prolong cycles ( $>200)$. This can be ascribed to the losing of hydroxyl group and phenolic resin frameworks in the carbon shell, as corfirmed by the ${ }^{13} \mathrm{C}$ NMR data of Si@10C-900 (Figure S4). Another interesting phenomena is that the electrochemical performance of the phenolic resinbased carbon interfacial layer can be easily effected by the different binders. As shown in the Figure S5, carboxymethyl cellulose (CMC) is considered as a more suitable binder than the sodium alginate and rendered long-term cycling stability with promising performance due to the formation of strong hydrogen bond and interaction between the phenolic resin frameworks surface and $\mathrm{CMC}$ carboxylic moieties. More importantly, to further evaluated the electrochemical cycling performance of Si@10C core shell nanoparticles under deep chargedischarge, the electrode is test at a current density as high as $2 \mathrm{~A} \mathrm{~g}^{-1}$. After kinetic enhancements at $140 \mathrm{~mA} \mathrm{~g}^{-1}$ for the first 5 cycles, an electrode capacity of $483 \mathrm{~mA} \mathrm{~h} \mathrm{~g}^{-1}$ is still maintained after 1000 cycles, which is much higher than the theoretical capacity of commercial graphite anode (Figure S6). Significantly, the high Coulombic efficiency is also obtained, especially in the prolonged cycles.[59] The average Coulombic efficiency from 200th to 1000th cycles of the $\mathrm{Si} @ 10 \mathrm{C}$ core shell nanoparticles is as high as $99.4 \%$. The finding with high Coulombic efficiency achieved here is consistent with the formation of stable SEI film on the surface of Si@10C core shell nanoparticles. 


\section{Conclusions}

In summary, we have demonstrated the fabrication of phenolic resin-based carbon interfacial coating on the surface of silicon nanoparticles by a simple surfactant templating sol-gel method. The fabricated carbon interfacial layers have uniform core-shell structure, controllable thickness of 2-25 nm, worm-like microporous, and phenolic resin frameworks. These phenolic resin-based carbon coated silicon nanoparticles show unique features with a significantly improved electrochemical performance, The core-shell nanoparticles with a $10 \mathrm{~nm}$-thick carbon coating possess the optimal electrochemical properties with a stable SEI film formation, and can be deeply cycled up to 500 times with capacity remaining at $1006 \mathrm{~mA} \mathrm{~h} \mathrm{~g}^{-1}$, as well as the high Coulombic efficiency of $>99.5 \%$. In addition, our carbon coating synthesis process is simple, scalable, and applicable to other high-performance electrode materials. 


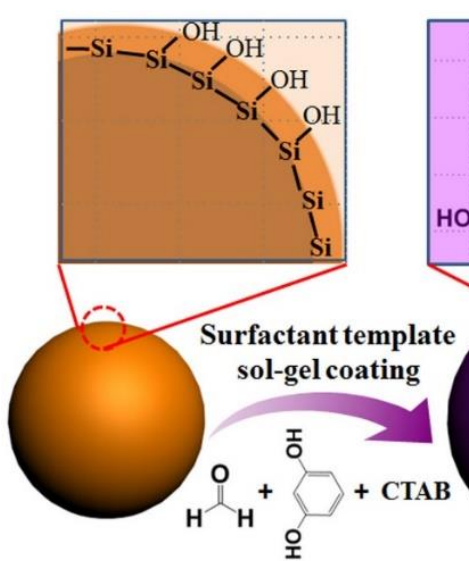

Si NPs

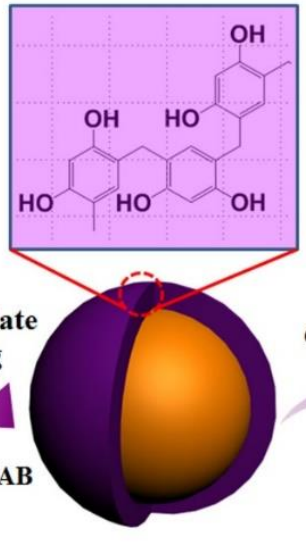

$\mathrm{Si} a \mathrm{RF}$

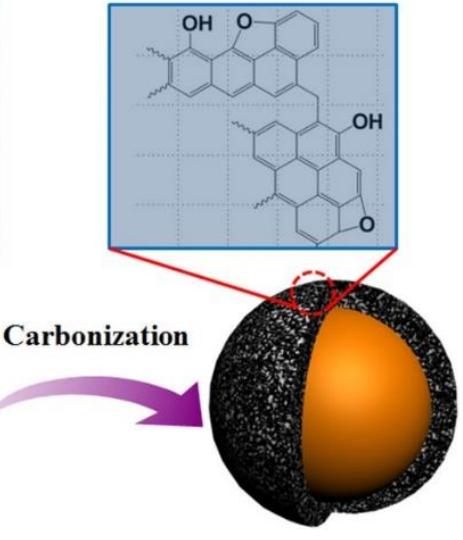

Si $a$ micro-C

Figure 1. Schematic illustration of the fabrication of phenolic resin-based carbon interfacial layer coated commercial silicon nanoparticles through the surfactant template sol-gel approach. 


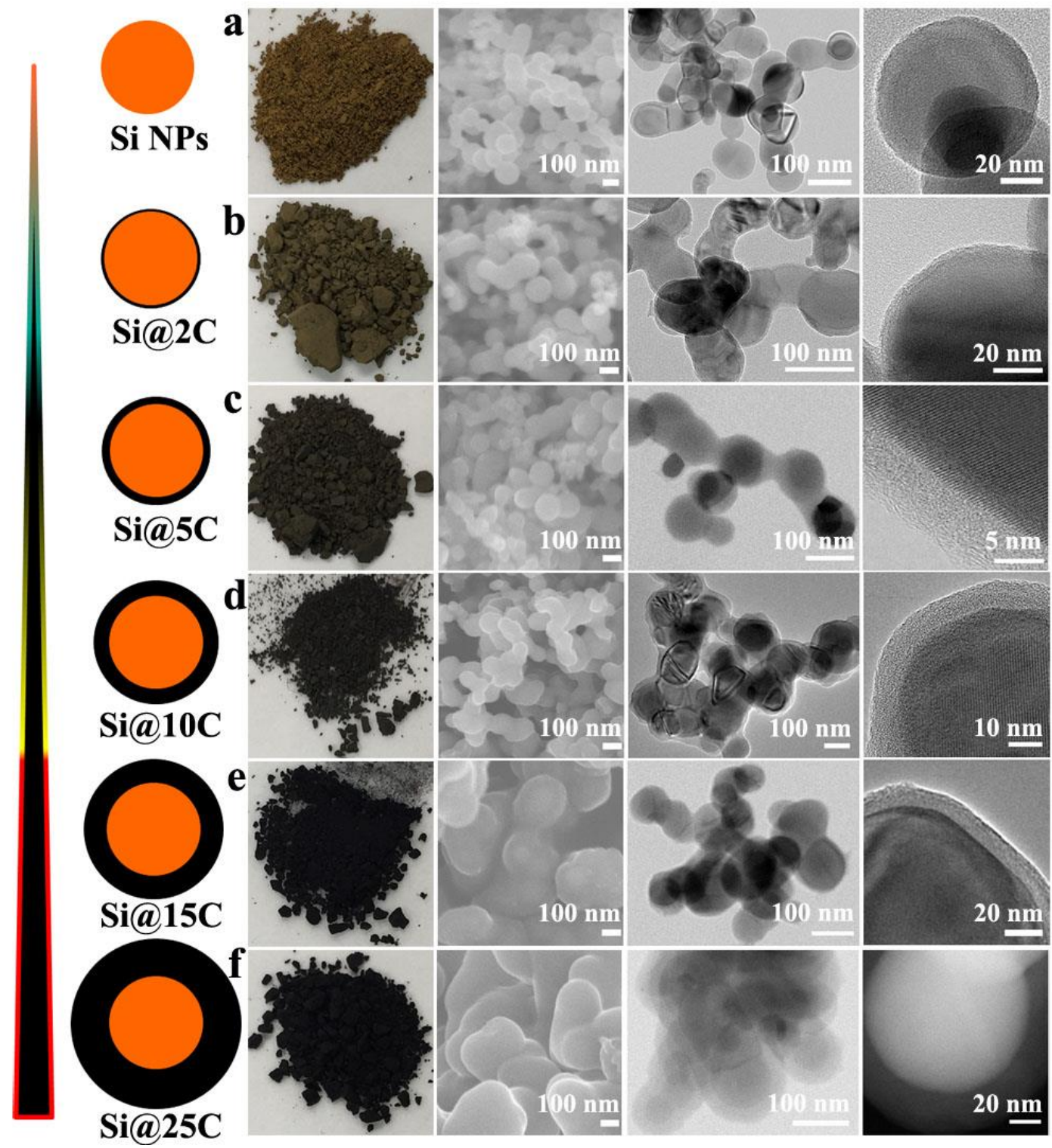

Figure 2. Optical, SEM and TEM images of Si@C core-shell nanoparticles with controllable coating thickness of: a) $0 \mathrm{~nm}$, b) $2 \mathrm{~nm}$, c) $5 \mathrm{~nm}$, d) $10 \mathrm{~nm}$, e) $15 \mathrm{~nm}$, and f) $25 \mathrm{~nm}$, respectively. 

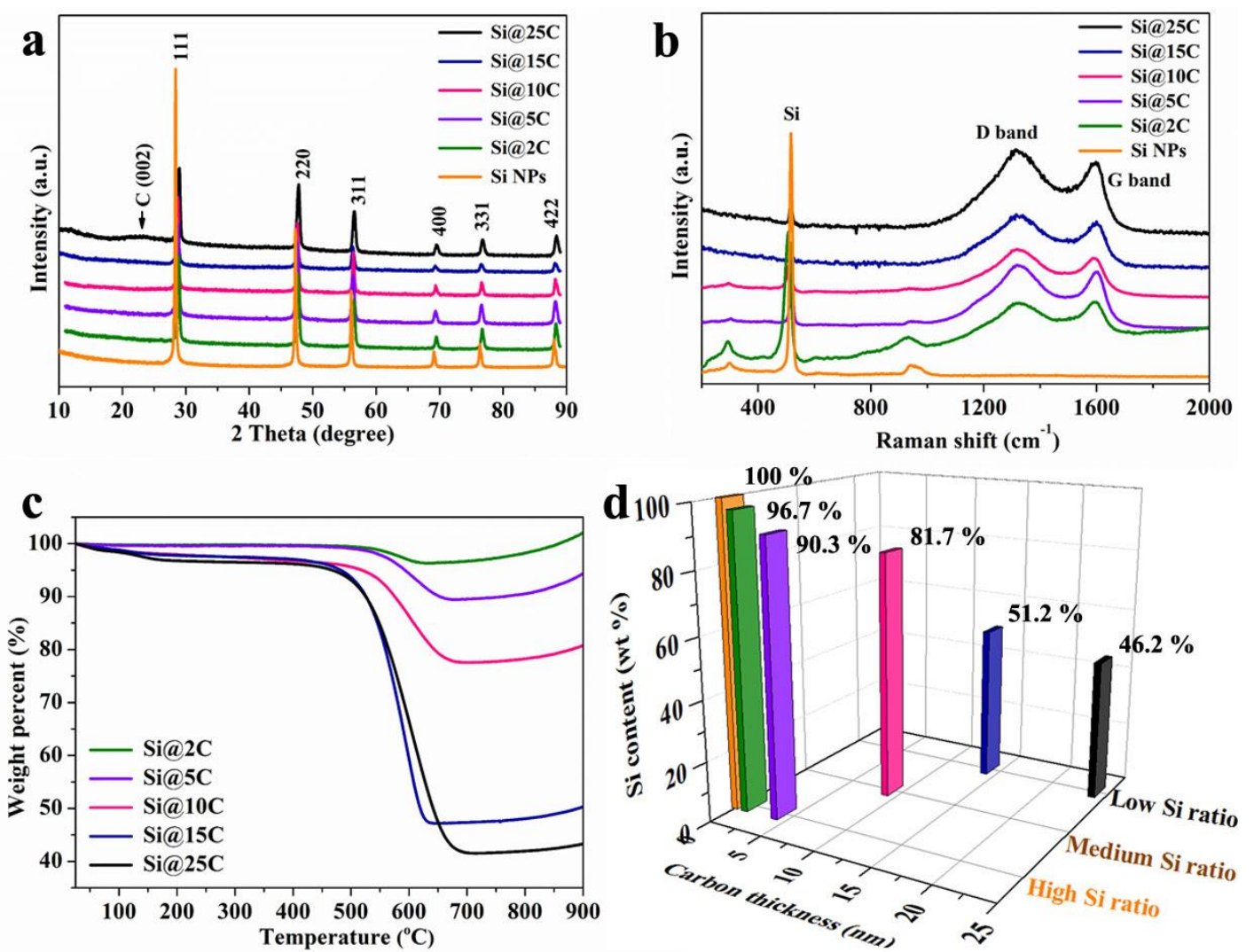

Figure 3. a) XRD pattern, b) Raman spectra, c) TG curves in air of carbon coated silicon coreshell nanoparticles with controllable layer thickness. d) The category of Si@xC samples based on the carbon layer thickness and Si content. 

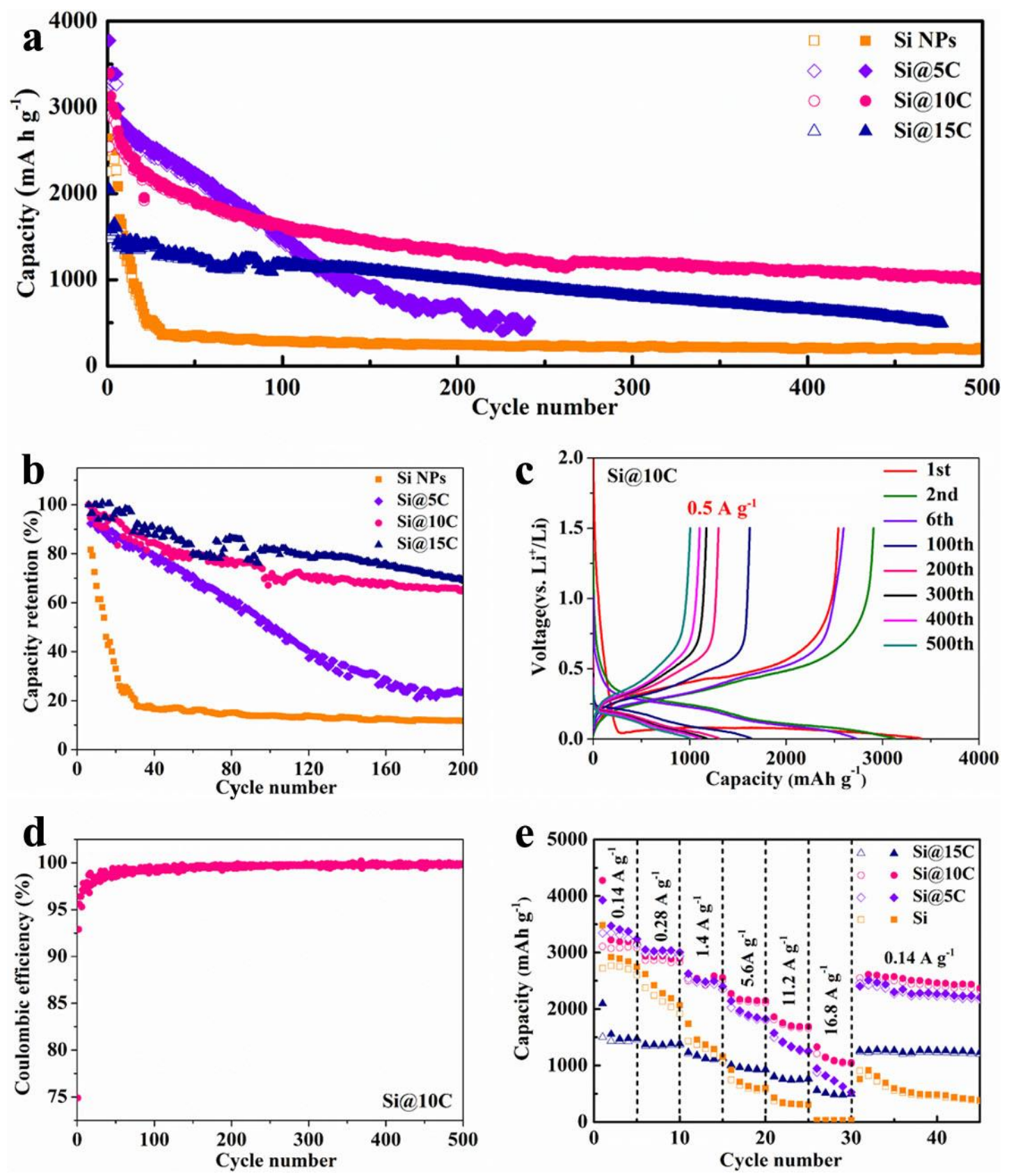

Figure 4. Electrochemical properties of carbon coated silicon core-shell nanoparticles with controllable layer thickness. a) Charge-discharge cycling performance (based on the total weight of the electrode) and b) capacity retention of Si NPs, Si@5C,Si@10C, and Si@15C electrodes at a current density of $500 \mathrm{~mA} \mathrm{~g}^{-1}$. c) Galvanostatic charge-discharge profiles for selected cycles and d) Coulombic efficiency of 10 nm-thick coating Si@10C core-shell nanoparticles. e) Charge and discharge capacities of Si NPs, Si@5C, Si@10C, and Si@15C electrodes at various current density ranging from 0.14 to $16.8 \mathrm{~A} \mathrm{~g}^{-1}$. 
Table 1. Discharge-charge capacity, initial Coulombic efficiency (ICE), and capacity retention after 500 cycles at the current density of $0.5 \mathrm{~A} \mathrm{~g}^{-1}$ of the carbon coated silicon core-shell nanoparticles with controllable layer thickness.

\begin{tabular}{cccccccc}
\hline Si ratio & Samples & $\begin{array}{c}\text { Carbon } \\
\text { thickness } \\
(\mathrm{nm})\end{array}$ & $\begin{array}{c}\text { Silicon } \\
\text { content } \\
(\mathrm{wt} \%)\end{array}$ & $\begin{array}{c}\text { Discharge } \\
\text { capacity } \\
\left(\mathrm{mA} \mathrm{h} \mathrm{g}^{-1}\right)\end{array}$ & $\begin{array}{c}\text { Charge } \\
\text { capacity } \\
\left(\mathrm{mA} \mathrm{h} \mathrm{g}^{-1}\right)\end{array}$ & $\begin{array}{c}\text { ICE } \\
(\%)\end{array}$ & $\begin{array}{c}\text { Capacity after } \\
500 \text { cycle } \\
\left(\mathrm{mA} \mathrm{h} \mathrm{g}^{-1}\right)\end{array}$ \\
\hline \multirow{2}{*}{ High } & Si NPs & 0 & 100 & 3105 & 2254 & 72.6 & $205(500$ th $)$ \\
& Si@2C & 2 & 96.7 & & & & \\
Medium & Si@5C & 5 & 90.3 & 3774 & 3238 & 85.8 & $443(240$ th $)$ \\
Low & Si@10C & 10 & 81.7 & 3394 & 2542 & 74.9 & $1006(500$ th) \\
& Si@25C & 15 & 51.2 & 2044 & 1473 & 72.1 & $494(477$ th) \\
\hline
\end{tabular}
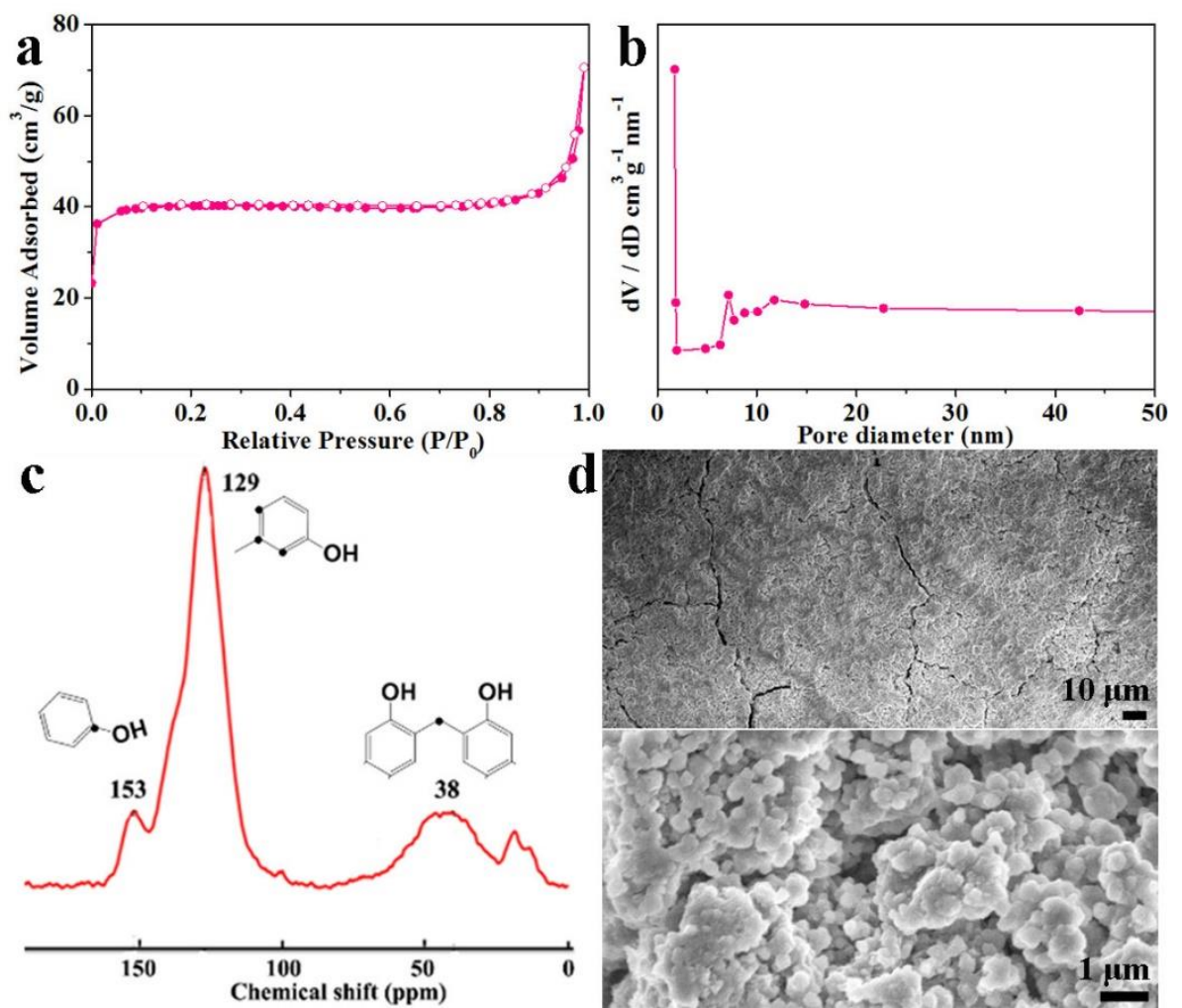

Figure 5. Characterization of physicochemcial properties of Si@ 10C core-shell nanoparticles. a) $\mathrm{N}_{2}$ adsorption-desorption isotherm curves, b) pore size distribution plot and c) ${ }^{13} \mathrm{C}$ solid-state NMR spectrum of Si@10C core-shell nanoparticles obtained after calcination in nitrogen atmosphere at $700{ }^{\circ} \mathrm{C}$. d) SEM images of Si@10C core-shell electrode after 500 cycles at a current density of $500 \mathrm{~mA} \mathrm{~g}^{-1}$. 
Table 2. Comparison of the synthesis method, carbon source and electrochemical performance of various carbon-coated silicon core-shell and yolk-shell nanocomposites.

\begin{tabular}{|c|c|c|c|c|c|c|}
\hline Sample & $\begin{array}{l}\text { Synthesis } \\
\text { method }\end{array}$ & $\begin{array}{l}\text { Carbon } \\
\text { source }\end{array}$ & $\begin{array}{l}\mathrm{Si} \\
(\mathrm{wt} \\
\%)\end{array}$ & $\begin{array}{l}\text { Current } \\
\text { density } \\
\left(\mathrm{mA} \mathrm{g}^{-1}\right)\end{array}$ & $\begin{array}{c}\text { Capacity } \\
\left(\mathrm{mA} \mathrm{h} \mathrm{g}^{-1}\right) \text { after } \\
\text { (n) cycles }\end{array}$ & $\begin{array}{l}\text { Refer } \\
\text { ences }\end{array}$ \\
\hline $\begin{array}{c}\mathrm{Si} @ 10 \mathrm{C} \\
\text { nanoparticles }\end{array}$ & sol-gel & $\begin{array}{l}\text { phenolic } \\
\text { resins }\end{array}$ & 81.7 & 500 & $1006(500)$ & $\begin{array}{l}\text { This } \\
\text { work }\end{array}$ \\
\hline $\begin{array}{l}\text { Carbon-coated Si } \\
\text { nanocomposites }\end{array}$ & spray-pyrolysis & $\begin{array}{l}\text { citric } \\
\text { acid }\end{array}$ & 44 & 100 & $1489(20)$ & 15 \\
\hline $\begin{array}{c}\mathrm{Si} @ \mathrm{SiO}_{\mathrm{x}} @ \mathrm{C} \\
\text { nanocomposites }\end{array}$ & hydrothermal & glucose & 75 & 150 & $1100(60)$ & 16 \\
\hline $\begin{array}{c}\text { Si@micro-C } \\
\text { nanocomposites }\end{array}$ & $\begin{array}{c}\text { in situ } \\
\text { polymerization }\end{array}$ & $\begin{array}{c}\text { PZS } \\
\text { polymer }\end{array}$ & 78 & 500 & $1201(40)$ & 20 \\
\hline $\begin{array}{c}\mathrm{Si} @ \mathrm{C} \\
\text { nanoparticles }\end{array}$ & pyrolysis & $\begin{array}{l}\text { polyvinylid } \\
\text { ene fluoride }\end{array}$ & 95.7 & 50 & $1290(30)$ & 19 \\
\hline $\begin{array}{c}\text { hollow Si@C } \\
\text { nanocomposites }\end{array}$ & $\begin{array}{l}\text { chemical vapor } \\
\text { deposition }\end{array}$ & toluene & 37 & 100 & $767(100)$ & 49 \\
\hline $\begin{array}{c}\text { C@void@Si } \\
\text { yolk-shell }\end{array}$ & $\begin{array}{l}\text { chemical vapor } \\
\text { deposition }\end{array}$ & acetylene & 30 & 250 & $1080(200)$ & 18 \\
\hline $\begin{array}{c}\text { Si@void@C } \\
\text { nanocomposites }\end{array}$ & alkaline etching & dopamine & 75 & 1000 & $804(50)$ & 17 \\
\hline Si pomegranate & $\begin{array}{l}\text { water-in-oil } \\
\text { emulsions }\end{array}$ & $\begin{array}{l}\text { phenolic } \\
\text { resins }\end{array}$ & 77 & 2100 & $1160(1000)$ & 42 \\
\hline
\end{tabular}




\section{ACKNOWLEDGMENT}

We acknowledge financial support from the China Postdoctoral Science Foundation (2014M551455 and 2015T80451), National Natural Science Foundation of China (No. 51402049), the Shanghai Committee of Science and Technology, China (No. 14ZR1400600), the

Fundamental Research Funds for the Central Universities (No. 2232015D3-06), the Programme of Introducing Talents of Discipline to Universities (No.111-2-04). We also thank the Commonwealth of Australia through the Automotive Australia 2020 Cooperative Research Centre (Auto CRC 2020), and Baosteel-Australia joint research and development center (Baosteel Grant no. BA14006).

\section{REFERENCES}

[1] J. Liu, P. Kopold, P.A. van Aken, J. Maier, Y. Yu, Angew. Chem. 127 (2015) 9768-9772.

[2] B. Scrosati, J. Hassoun, Y.-K. Sun, Energy Environ. Sci. 4 (2011) 3287-3295.

[3] M. Gu, Y. He, J. Zheng, C. Wang, Nano Energy 17 (2015) 366-383.

[4] S.W. Oh, S.T. Myung, S.M. Oh, K.H. Oh, K. Amine, B. Scrosati, Y.K. Sun, Adv. Mater. 22 (2010) 4842-4845.

[5] C. Li, H. Zhang, L. Fu, H. Liu, Y. Wu, E. Rahm, R. Holze, H. Wu, Electrochimica Acta 51 (2006) 3872-3883.

[6] X. Xiao, W. Zhou, Y. Kim, I. Ryu, M. Gu, C. Wang, G. Liu, Z. Liu, H. Gao, Adv. Funct. Mater. 25 (2015) 1426-1433.

[7] J. Saint, M. Morcrette, D. Larcher, L. Laffont, S. Beattie, J.P. Pérès, D. Talaga, M. Couzi, J.M. Tarascon, Adv. Funct. Mater. 17 (2007) 1765-1774.

[8] S. Sim, P. Oh, S. Park, J. Cho, Adv. Mater. 25 (2013) 4498-4503.

[9] I.H. Son, J. Hwan Park, S. Kwon, S. Park, M.H. Rummeli, A. Bachmatiuk, H.J. Song, J. Ku, J.W. Choi, J.-m. Choi, S.-G. Doo, H. Chang, Nat. Commun. 6 (2015) 7393.

[10] M. Zhou, X. Li, B. Wang, Y. Zhang, J. Ning, Z. Xiao, X. Zhang, Y. Chang, L. Zhi, Nano Lett. 15 (2015) 6222-6228.

[11] F. Xia, S. Kwon, W.W. Lee, Z. Liu, S. Kim, T. Song, K.J. Choi, U. Paik, W.I. Park, Nano Lett. 15 (2015) 6658-6664.

[12] C. Martin, O. Crosnier, R. Retoux, D. Bélanger, D.M. Schleich, T. Brousse, Adv. Funct. Mater. 21 (2011) 3524-3530.

[13] C.-M. Wang, X. Li, Z. Wang, W. Xu, J. Liu, F. Gao, L. Kovarik, J.-G. Zhang, J. Howe, D.J. Burton, Z. Liu, X. Xiao, S. Thevuthasan, D.R. Baer, Nano Lett. 12 (2012) 1624-1632.

[14] L. Luo, P. Zhao, H. Yang, B. Liu, J.-G. Zhang, Y. Cui, G. Yu, S. Zhang, C.-M. Wang, Nano Lett. 15 (2015) 7016-7022. 
[15] S.-H. Ng, J. Wang, D. Wexler, K. Konstantinov, Z.-P. Guo, H.-K. Liu, Angew. Chem., Int. Ed. 45 (2006) 6896-6899.

[16] Y.-S. Hu, R. Demir-Cakan, M.-M. Titirici, J.-O. Müller, R. Schlögl, M. Antonietti, J. Maier, Angew. Chem., Int. Ed. 47 (2008) 1645-1649.

[17] L. Pan, H. Wang, D. Gao, S. Chen, L. Tan, L. Li, Chem. Commun. 50 (2014) 5878-5880.

[18] L. Zhang, R. Rajagopalan, H. Guo, X. Hu, S. Dou, H. Liu, Adv. Funct. Mate. 26 (2016) 440-446.

[19] Y. Xu, G. Yin, Y. Ma, P. Zuo, X. Cheng, J. Mater. Chem. 20 (2010) 3216-3220.

[20] P. Gao, J. Fu, J. Yang, R. Lv, J. Wang, Y. Nuli, X. Tang, Phys. Chem. Chem. Phys. 11 (2009) $11101-11105$.

[21] J. Guo, A. Sun, X. Chen, C. Wang, A. Manivannan, Electrochimica Acta 56 (2011) 39813987.

[22] Z. Lu, N. Liu, H.-W. Lee, J. Zhao, W. Li, Y. Li, Y. Cui, ACS Nano, 9 (2015) 2540-2547.

[23] J.R. Szczech, S. Jin, Energy Environ. Sci. 4 (2011) 56-72.

[24] R. Teki, M.K. Datta, R. Krishnan, T.C. Parker, T.-M. Lu, P.N. Kumta, N. Koratkar, Small 5 (2009) 2236-2242.

[25] B. Wang, X. Li, X. Zhang, B. Luo, M. Jin, M. Liang, S.A. Dayeh, S.T. Picraux, L. Zhi, ACS Nano 7 (2013) 1437-1445.

[26] W. Ren, Y. Wang, Z. Zhang, Q. Tan, Z. Zhong, F. Su, J. Mater. Chem. A 4 (2016) 552-560.

[27] Y. He, X. Yu, Y. Wang, H. Li, X. Huang, Adv. Mater. 23 (2011) 4938-4941.

[28] H. Wu, G. Yu, L. Pan, N. Liu, M.T. McDowell, Z. Bao, Y. Cui, Nat. Commun 4 (2013) 1943.

[29] Y. Chen, L. Liu, J. Xiong, T. Yang, Y. Qin, C. Yan, Adv. Funct. Mater. 25 (2015) 6701-6709.

[30] A. Gohier, B. Laïk, K.-H. Kim, J.-L. Maurice, J.-P. Pereira-Ramos, C.S. Cojocaru, P.T. Van, Adv. Mater. 24 (2012) 2592-2597.

[31] Y.-X. Yin, S. Xin, L.-J. Wan, C.-J. Li, Y.-G. Guo, J. Phys. Chem. C 115 (2011) 1414814154.

[32] N. Dimov, S. Kugino, M. Yoshio, Electrochimica Acta 48 (2003) 1579-1587.

[33] Z.S. Wen, J. Yang, B.F. Wang, K. Wang, Y. Liu, Electrochem. Commun. 5 (2003) 165-168.

[34] X.-W. Zhang, P.K. Patil, C. Wang, A.J. Appleby, F.E. Little, D.L. Cocke, J. Power Sources 125 (2004) 206-213.

[35] S.H. Ng, J. Wang, D. Wexler, S.Y. Chew, H.K. Liu, J. Phys. Chem. C 111 (2007) 1113111138.

[36] R. Zhang, Y. Du, D. Li, D. Shen, J. Yang, Z. Guo, H.K. Liu, A.A. Elzatahry, D. Zhao, Adv. Mater. 26 (2014) 6749-6755.

[37] Z. Zhang, Y. Wang, W. Ren, Q. Tan, Y. Chen, H. Li, Z. Zhong, F. Su, Angew. Chem., Int. Ed. 53 (2014) 5165-5169.

[38] Y. Chen, M. Xu, Y. Zhang, Y. Pan, B.L. Lucht, A. Bose, ACS Appl. Mater. Interfaces 7 (2015) 21391-21397.

[39] J.S. Kim, W. Pfleging, R. Kohler, H.J. Seifert, T.Y. Kim, D. Byun, H.-G. Jung, W. Choi, J.K. Lee, J. Power Sources 279 (2015) 13-20.

[40] Z. Sun, S. Tao, X. Song, P. Zhang, L. Gao, J. Electrochem. Soc. 162 (2015) A1530-A1536.

[41] L.Y. Yang, H.Z. Li, J. Liu, Z.Q. Sun, S.S. Tang, M. Lei, Sci. Rep. 5 (2015) 10908.

[42] N. Liu, Z. Lu, J. Zhao, M.T. McDowell, H.-W. Lee, W. Zhao, Y. Cui, Nat. Nanotechnol. 9 (2014) 187-192.

[43] J. Yang, Y.-X. Wang, S.-L. Chou, R. Zhang, Y. Xu, J. Fan, W.-x. Zhang, H. K. Liu, D. Zhao, 
S. X. Dou, Nano Energy 18 (2015) 133-142.

[44] S. Chen, M.L. Gordin, R. Yi, G. Howlett, H. Sohn, D. Wang, Phys. Chem. Chem. Phys. 14 (2012) 12741-12745.

[45] N. Liu, H. Wu, M.T. McDowell, Y. Yao, C. Wang, Y. Cui, Nano Lett. 12 (2012) 3315-3321.

[46] J. Kong, W.A. Yee, Y. Wei, L. Yang, J.M. Ang, S.L. Phua, S.Y. Wong, R. Zhou, Y. Dong, X. Li, X. Lu, Nanoscale 5 (2013) 2967-2973.

[47] B. Wang, X. Li, X. Zhang, B. Luo, Y. Zhang, L. Zhi, Adv. Mater. 25 (2013) 3560-3565.

[48] X.-y. Zhou, J.-j. Tang, J. Yang, J. Xie, L.-1. Ma, Electrochimica Acta 87 (2013) 663-668.

[49] H. Tao, L.-Z. Fan, W.-L. Song, M. Wu, X. He, X. Qu, Nanoscale 6 (2014) 3138-3142.

[50] L. Liu, J. Lyu, T. Li, T. Zhao, Nanoscale 8 (2016) 701-722.

[51] X. Zhou, L.-J. Wan, Y.-G. Guo, Small 9 (2013) 2684-2688.

[52] J. Liu, S.Z. Qiao, H. Liu, J. Chen, A. Orpe, D. Zhao, G.Q.M. Lu, Angew. Chem., Int. Ed. 50 (2011) 5947-5951.

[53] B. Guan, X. Wang, Y. Xiao, Y. Liu, Q. Huo, Nanoscale 5 (2013) 2469-2475.

[54] S. M. Hwang, Y.-G. Lim, J.-G. Kim, Y.-U. Heo, J. H. Lim, Y. Yamauchi, M.-S. Park, Y.-J. Kim, S. X. Dou, J. H. Kim, Nano Energy 10 (2014) 53-62.

[55] H. Nara, Y. Fukuhara, A. Takai, M. Komatsu, H. Mukaibo, Y. Yamauchi, T. Momma, K. Kuroda, T. Osaka, Chem. Lett. 37 (2008) 142-143.

[56] M. Pramanik, Y. Tsujimoto, V. Malgras, S. X. Dou, J. H. Kim, Y. Yamauchi, Chem. Mater. 27 (2015) 1082-1089.

[57] J. Liu, N. Li, M.D. Goodman, H.G. Zhang, E.S. Epstein, B. Huang, Z. Pan, J. Kim, J.H. Choi, X. Huang, ACS Nano 9 (2015) 1985-1994.

[58] H. Wu, G. Zheng, N. Liu, T.J. Carney, Y. Yang, Y. Cui, Nano Lett. 12 (2012) 904-909.

[59] S. Choi, D.S. Jung, J.W. Choi, Nano Lett. 14 (2014) 7120-7125. 